\title{
Effects of the MAOA gene and levels of exposure to violence on antisocial outcomes
}

Isabelle Ouellet-Morin, Sylvana M. Côté, Frank Vitaro, Martine Hébert, René Carbonneau, Éric Lacourse, Gustavo Turecki* and Richard E. Tremblay*

\section{Background}

The monoamine oxidase $\mathrm{A}(\mathrm{MAOA})$ gene has been shown to moderate the impact of maltreatment on antisocial behaviour. Replication efforts have, however, yielded inconsistent results.

\section{Aims}

To investigate whether the interaction between the MAOA gene and violence is present across the full distribution of violence or emerges at higher levels of exposure.

\section{Method}

Participants were 327 male members of the Québec Longitudinal Study of Kindergarten Children. Exposure to violence comprised retrospective reports of mother's and father's maltreatment, sexual and physical abuse. Conduct disorder and antisocial personality symptoms were assessed in semi-structured interviews and partner violence, propertyviolent crimes and arrest were self-reported.

\section{Results}

Non-linear interactions between the MAOA gene and violence were detected, suggesting that the genetic moderation may come about once a certain level of violence is experienced.

\section{Conclusions}

Future studies should investigate the mechanisms translating substantial violence exposure, which could, subsequently, trigger the expression of genetically based differences in antisocial behaviour.

\section{Declaration of interest}

None.

\section{Copyright and usage}

(c) The Royal College of Psychiatrists 2016.
Understanding how early environments affect trajectories of social, emotional and behavioural problems is the core objective of several lines of research in human development. There is substantial heterogeneity at the root of these trajectories, even among individuals exposed to similar living circumstances; although some individuals seem to thrive under harsh living conditions, others are affected by minimal disruptions in their environments. ${ }^{1,2}$ Adverse environments such as maltreatment lead to antisocial outcomes only in a fraction of individuals. ${ }^{3}$ Identifying the mechanisms underlying this heterogeneity is an important step towards improving our understanding of antisocial behaviour and informing prevention efforts. Genetically informative studies indicate that genes and environments explain individual differences in antisocial behaviour. ${ }^{4}$ However, these contributions may not be independent. ${ }^{5}$ For example, twins with the highest genetic risk at age 5 showed the greatest impact of maltreatment on conduct disorder. ${ }^{6}$ Phenotypic heterogeneity following exposure to maltreatment may lie, to some extent, in differences present at the DNA level. Genes $\times$ environment interaction (GE) occurs when the effect of an environment on a phenotype is conditional on a person's genotype. ${ }^{7}$ In a seminal paper published by Caspi and colleagues in 2002, the impact of childhood maltreatment on antisocial personality, conduct disorder and violent crimes was magnified by an allele conferring low activity of the monoamine oxidase A (MAOA) gene. ${ }^{8}$ Importantly, differences between low- and high-allele carriers were present only when exposed to childhood maltreatment, but not otherwise. MAOA is an enzyme that preferentially degrades monoamines such as noradrenaline, serotonin and dopamine and is presumed to affect antisocial behaviour indirectly, through the disruption of neurotransmitter balance in brain structures and

*These authors share senior authorship. neural pathways involved in emotional regulation and behavioural inhibition. ${ }^{9}$

The moderating impact of the MAOA gene on the association linking childhood maltreatment to antisocial outcomes has been replicated, ${ }^{10-12}$ but not consistently. ${ }^{13,14}$ Several methodological issues may explain these discrepancies, including diverse sample populations (for example clinical or forensic $v$. populationbased), ${ }^{14}$ population genetic heterogeneity ${ }^{13}$ and exposure to distinct adverse environments, varying from maltreatment, ${ }^{15}$ to type of residence ${ }^{16}$ and stressful life events. ${ }^{17}$ Even when only maltreatment is considered, inconsistency remains that may partially lie in how this variable was measured (such as official reports, structured interviews, self-reports) and later analysed. Specifically, exposure to violence is a quantitative variable that is, in its natural state, continuously distributed in the population. Most studies have thus far used artificially truncated measures, making it difficult to determine whether the moderating effect of the MAOA gene takes place across the full distribution of exposure or emerges whenever a yet unknown level of violence has been reached, as the diathesis-stress model suggests. Importantly, the level of exposure at which the moderating effect of the MAOA gene likely emerges cannot be deduced from studies assuming a constant increment of the interaction across the distribution of violence. Past investigations may thus not provide a comprehensive account of the moderating role of the MAOA gene to antisocial behaviour. The aim of the study was to investigate whether the MAOA gene moderates the impact of childhood exposure to violence on antisocial outcomes in a population-based sample of males. The objectives were threefold. First, we examined the main and interaction effects of the MAOA gene across the full distribution of violence. Second, we tested whether the MAOA gene affects risks of antisocial outcomes at higher level of exposure. Third, we investigated whether similar findings emerge for distinct antisocial outcomes. 


\section{Method}

\section{Participants}

The Québec Longitudinal Study of Kindergarten Children (QLSKC) was created from a larger sample of children. A first subsample comprised 2000 children (999 girls and 1001 boys) selected randomly to represent children attending kindergarten in French-speaking state schools of the province of Québec, Canada. The second subsample included all remaining children who scored at the eightieth percentile or higher $(n=1017,424$ girls and 593 boys, with gender-specific cut-offs) on disruptive behaviour. Teachers and mothers rated these behaviours using 13 items from the Social Behavior Questionnaire, ${ }^{18}$ covering physical aggression, opposition, hyperactivity and antisociality (i.e. lying, cheating and stealing). Factor analyses suggested that these items belonged to a single factor for which high internal consistency was noted (Cronbach's alpha from 0.86 to 0.90 and 0.82 to 0.89 for mothers and teachers respectively). A total initial sample of 3017 children was thus created. At 21 years old, men were invited to a follow-up assessment. Participants for whom DNA was not collected were more likely to be from a family with a low socioeconomic status $(t(1,469.76)=-6.40, P<0.001)$ and have externalising problems as children $(t(1,528.25)=-3.70$, $P<0.001)$. All statistical analyses have thus been conducted using weights to compensate for this selective attrition. We only include self-reported White participants to reduce genetic heterogeneity. The study was approved by the research ethics board of Université de Montréal and McGill University. Written informed consents were obtained.

\section{Measures}

\section{Genotyping}

Common tag single nucleotide polymorphisms (SNPs, minor allele frequency $>5 \%$ ) and SNPs located $5 \mathrm{kbp}$ upstream of the transcription site were selected. Tag SNPs were obtained using Hapmap for the Utah residents with ancestry from northern and western Europe $(\mathrm{CEU})^{19}$ and the Multimarker tagging procedure $\left(r^{2}>0.8\right)$ using Tagger. ${ }^{20}$ Additionally, 44 anonymous markers spread across the genome and located outside of genecoding regions were genotyped to detect population stratification. We used a high-throughput, 768-SNP Illumina platform and GoldenGate panel based on BeadArray technology. The initial genotyping success rate for the SNPs was $95.4 \%$. SNPs less than 60 base pairs apart were eliminated, 33 SNPs were eliminated because of call rate $<0.90$ and 14 participants were discarded because of low average call rates $(<0.95)$. Based on the pattern of linkage disequilibrium between the 23 genotyped SNPs (online Fig. DS1), we selected a maximally informative set of SNPs (rs5906893, rs5906957, rs2283725, rs2072744, rs979605) using an algorithm published by Carlson et $a l^{21}$ and a stringent threshold $\left(r^{2} \geqslant 0.90\right)$ to capture most individual variation. Each SNP was tested separately to enhance the sensitivity of our investigations.

\section{Population stratification}

Even though the French Canadian population has descended from a small number of founders, ${ }^{22}$ we identified 12 population outliers using the genotype log likelihood test statistic with a standard cut-off of -2.33 , corresponding to a $P$-value of 0.001 of $n(0,1)$. The final sample thus included 327 participants.

\section{Exposure to violence}

Exposure to violence was based on four indicators collected retrospectively when the participants were 21 years of age. Mother's and father's maltreatment encompassed psychological aggression and physical assaults that have occurred before age 18 using an adapted version of the Revised Conflict Tactics Scales. ${ }^{23}$ Good internal reliability was noted (Cronbach's $\alpha=0.85$ and 0.83 respectively) and this measure was associated to expected outcomes in this cohort (such as depression and suicide attempts). Scores varied from 0 to 64 (mean 8.47, s.d. $=8.73$ ) and 0 to 41 (mean 8.66 , s.d. $=8.01$ ) respectively. Sexual abuse was assessed using five items adapted from the Adverse Childhood Experiences (ACE) Study ${ }^{24}$ and the Sexually Victimized Children Questionnaires, ${ }^{25}$ reflecting experiences of unwanted sexual acts (such as exhibitionism, sexual fondling and completed or attempted sexual intercourse; Cronbach's $\alpha=0.65)$. This measure predicted later sexual problems and high-risk sexual behaviour in this cohort. ${ }^{26}$ Participants who answered 'yes' to any of these questions were classified as having experienced sexual abuse. Physical abuse experienced before age 18 at the hands of a mother or father figure was measured using eight items of the Parent-Child Conflict Tactics Scale (Cronbach's $\alpha=0.64) .{ }^{23}$ Physical abuse was associated with later verbal and physical aggression in this cohort. ${ }^{27}$ A total of $23(7.0 \%)$ and 80 participants $(24.5 \%)$ reported sexual and physical abuse respectively. A confirmatory factorial analysis confirmed that these indicators could be grouped into one factor (root mean square error of approximation (RMSEA) $=0.045$; comparative fit index $(\mathrm{CFI})=0.918$; Tucker-Lewis Index $(\mathrm{TLI})=0.901)$. Except when otherwise mentioned, we have conducted the analyses according to five equal groups exposed to incremental levels of violence to avoid making comparisons on small numbers of observations.

\section{Antisocial outcomes}

Conduct disorder symptoms were assessed at age 15 using a semistructured interview based on the Diagnostic Interview Schedule for Children (DISC) ${ }^{28}$ and conducted by trained research assistants. The reliability of the French version of the DISC is satisfactory. ${ }^{29}$ A total was created by summing up the criteria (range $0-11$, mean $1.47($ s.d. $=1.81))$. Antisocial personality symptoms were measured at age 21 in a similar interview, the Diagnostic Interview Schedule (DIS) for adults, also based on the DSM-III-R criteria (such as illegal activities, impulsivity and remorselessness). ${ }^{30} \mathrm{~A}$ total was obtained by summing up the criteria (range 0-11, mean 1.47 $($ s.d. $=1.81)$ ). Property-violent crimes was assessed using 10 items (such as stealing, fraud and burglary) included in the life events calendar conducted when the participants were 21 years old. ${ }^{31}$ We scored each behaviour as absent or present in the past year and identified 35 participants $(10.7 \%)$ who reported at least one property crime. The occurrence of violent crimes during the past year was assessed using eight items drawn from the DIS ${ }^{30}$ and the Dimensional Assessment of Personality Pathology - Basic Questionnaire. ${ }^{32}$ A total of 28 participants $(8.6 \%)$ reported at least one violent crime. When combined, 58 participants $(17.7 \%)$ committed either property or violent crimes. Arrest was measured using the life events calendar by asking participant to recall whether they have ever been arrested as an adult or juvenile. A total of 59 participants (18.0\%) did. Physical partner violence was measured at 21 years using 15 items of the Conflict Tactics Scale ${ }^{23}$ including items such as pushed/grabbed/shoved; choked/ strangled; threatened with knife/gun. A total was created by summing up the item (range 0-11, mean 1.47 (s.d.=1.81)).

\section{Statistical analyses}

Preliminary analyses

In a series of ANOVAs, we detected comparable levels of violence between the MAOA alleles $\left(F_{s}(1,325)\right.$ varied from 0.07 to 0.85 , all $P_{s}>0.35$ ), suggesting that the participants' genotype should not have affected violence experiences. However, mothers' antisocial 
personality (measured when the participants were age 15 using the DIS for adults) ${ }^{30}$ was associated with their son's exposure to violence $(F(2,324)=5.06, P=0.007)$. We controlled for this potential confounder in all subsequent analyses by including this variable in the model along with the main and interaction effects to avoid bias associated with passive gene-environment correlations.

\section{Main analyses}

First, we tested the main and interaction (linear and non-linear) effects of the MAOA gene and exposure to violence on antisocial outcomes using weighted least squares analyses (with robust estimators). Second, we examined whether linear or quadratic functions best described the associations between violence and each outcome according to an SNP (rs2283725) in high linkage disequilibrium with the others. Significant quadratic associations among one group but not the other would suggest that the genetic moderation materialises only when a yet unidentified threshold of violence is reached. We then followed an analytical strategy adapted from Weder et al to test whether the interaction could take place only among individuals exposed to higher levels of violence. ${ }^{15}$ To do so, the interaction is estimated across the distribution (grouped in deciles) and then at increasing levels of violence through setting the interaction term to ' 0 ' (one decile at the time). The total sample was thus always included in the analyses.

\section{Results}

\section{Main effects of the MAOA gene and violence on antisocial outcomes}

Exposure to violence was associated with more symptoms of conduct disorder in adolescence and antisocial personality in adulthood and a higher probability of arrest and partner violence (Table 1, Model 1). No clear association was noted for property- violent crimes. Two out of five MAOA SNPs uniquely contributed to conduct disorder symptoms and all five were associated with antisocial personality symptoms and partner violence once exposure to violence and maternal antisocial personality were accounted for. That is, low-frequency allele carriers had more conduct disorder and antisocial personality symptoms and reported more partner violence in comparison with high-frequency allele carriers. Online Table DS1 presents the bivariate associations between MAOA SNPs and antisocial outcomes.

\section{Interaction between violence and MAOA gene on antisocial outcomes}

Table 1 (Model 2) presents the tests of linear and non-linear interactions between the MAOA SNPs, exposure to violence and antisocial outcomes. Only conduct disorder symptoms and partner violence showed significant linear interaction between the gene and the environment (GE). Significant non-linear models were uncovered for antisocial personality symptoms, in addition to conduct disorder and partner violence. The Wald chi-squared estimates of GE also increased for property-violent crimes but did not reach significance. Also suggesting that a magnified risk of antisocial outcomes may come about at higher levels of exposure is the observation that quadratic associations tend to be present (albeit not always significant at $\alpha=0.05$ ) among the low-frequency allele carriers for conduct disorder (Wald $\chi^{2}=5.61(1), P=0.02$ ), antisocial personality (Wald $\chi^{2}=3.23(1)$, $P=0.07$ ), property-violent crimes (Wald $\chi^{2}=7.34(1), P=0.007$ ) and partner violence (Wald $\chi^{2}=3.23(1), P=0.07$ ). Conversely, only linear associations were noted between violence and conduct disorder among the high-frequency allele carriers (Wald $\chi^{2}=11.65(1), P=0.001$ ), antisocial personality symptoms (Wald $\chi^{2}=12.58(1), \quad P<0.001$ ) and partner violence (Wald $\left.\chi^{2}=12.63(1), P<0.001\right)$. No linear or quadratic associations were

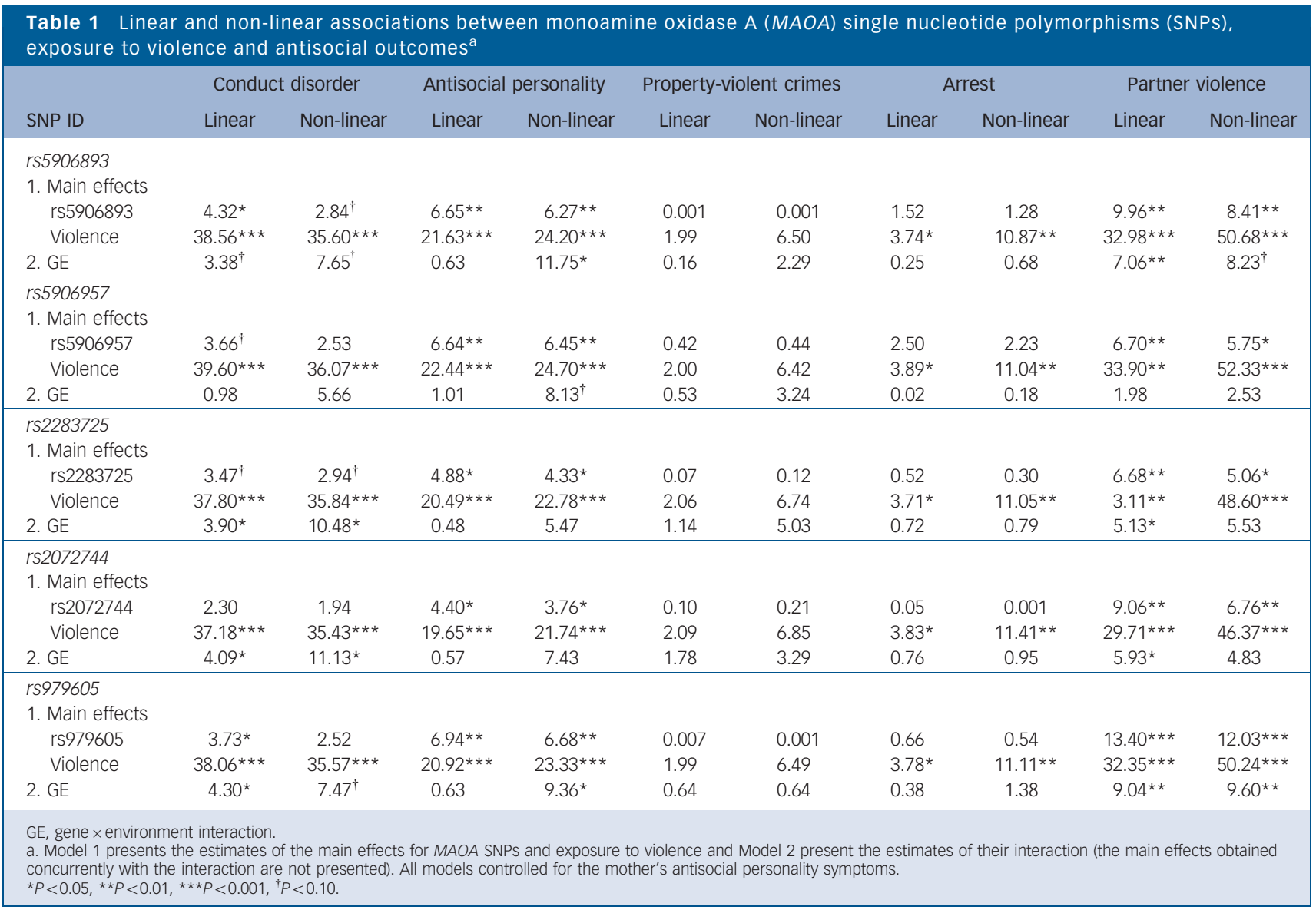


detected for the history of arrest. Figure 1 shows that low-frequency allele carriers (rs2283725) had more symptoms of conduct disorder and antisocial personality and reported more propertyviolent crimes, arrests and partner violence than high-frequency allele carriers when exposed to higher levels of violence.

\section{Exploratory sensitivity analyses}

Figure 2 presents the Wald chi-squared estimates of the interaction between the MAOA SNPs and violence once the main effects of (a)
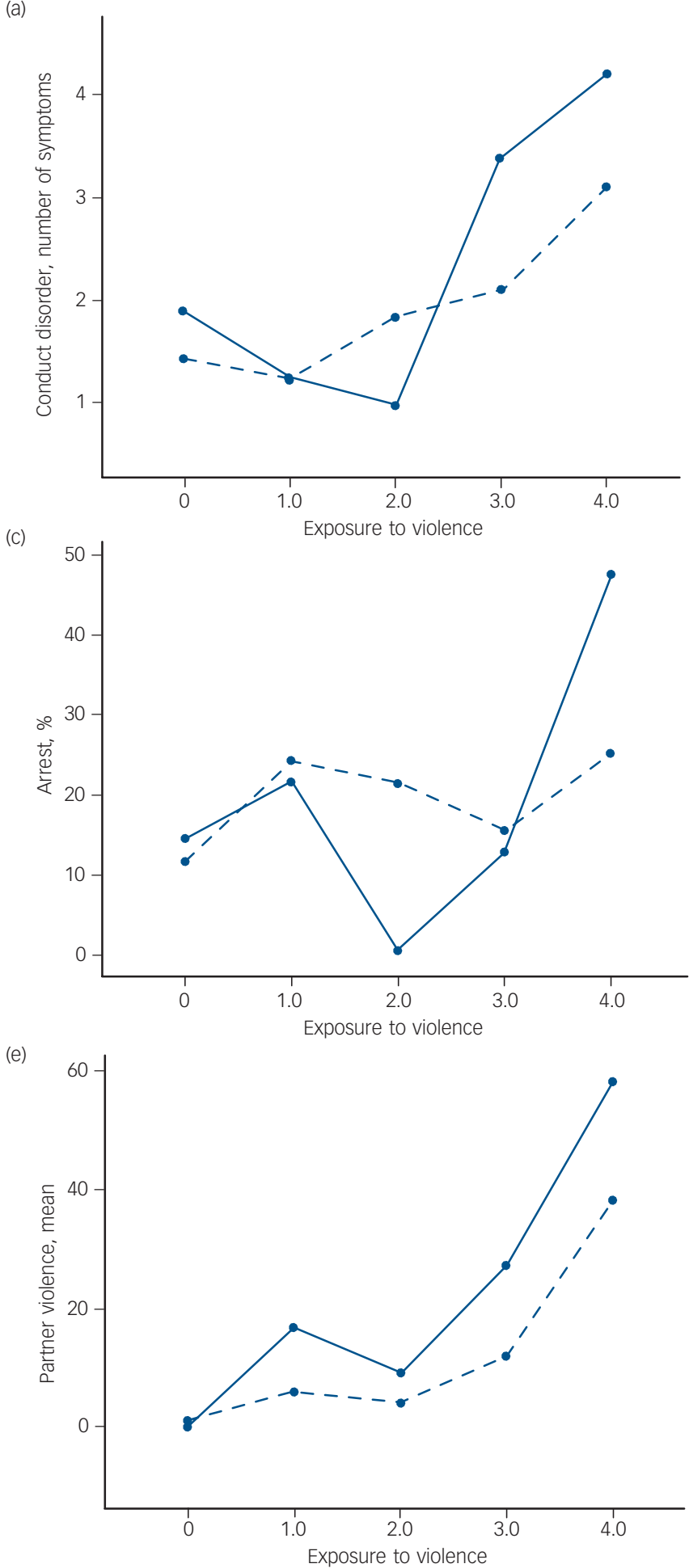

these variables, mothers' antisocial personality and selective attrition were accounted for. After testing the interaction across the full distribution, we repeat our tests while assuming that the interaction took place only at higher levels of violence (one decile at the time). The interaction coefficients became gradually larger, and eventually significant, when no interactions were assumed to occur at lower levels of exposure for conduct disorder and antisocial personality symptoms and property-violent crimes. A similar pattern of findings was detected for arrest without
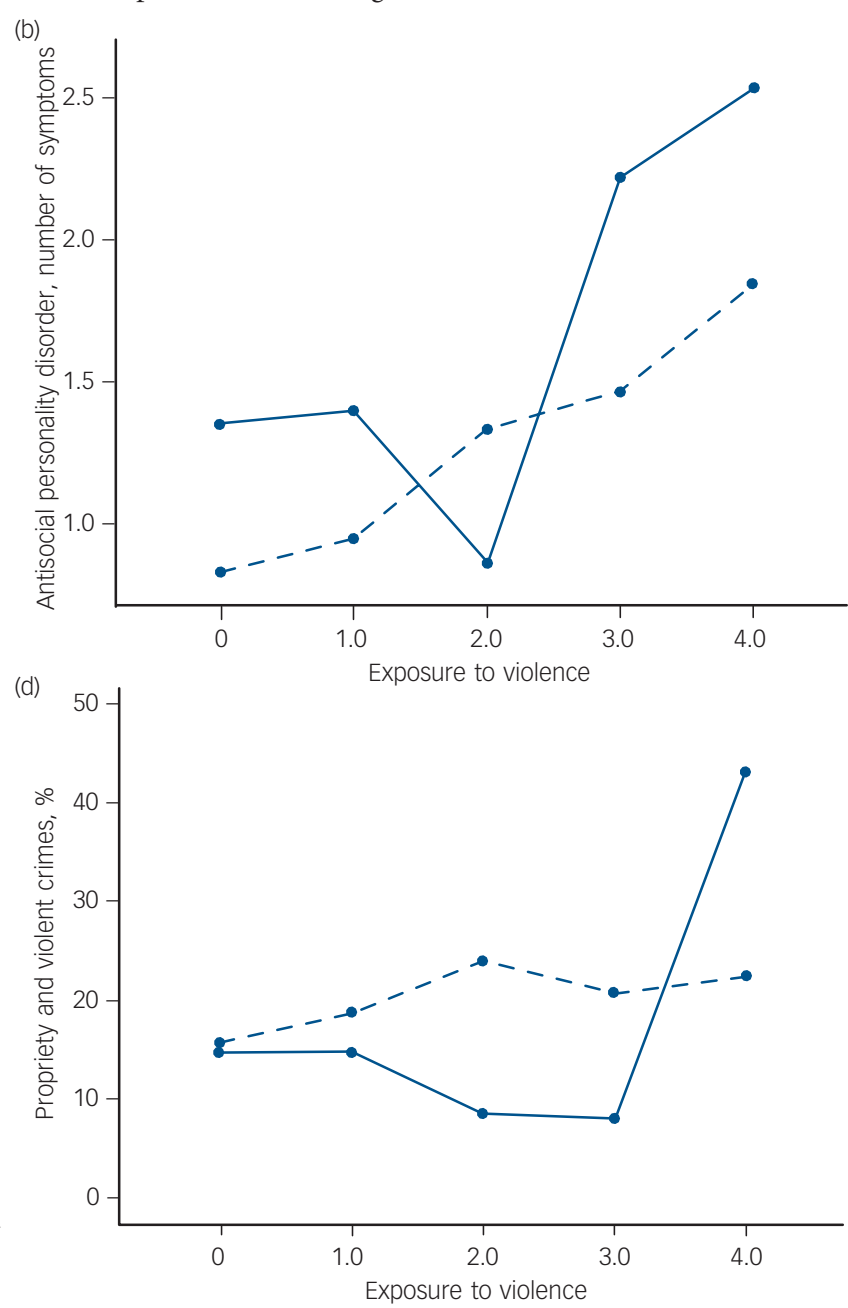

Fig. 1 Association between childhood exposure to violence and antisocial outcomes according to the monoamine oxidase A (MAOA) genotype (rs2283725).

(a) Conduct disorder, (b) antisocial personality disorder, (c) arrest, (d) property and violent crimes, and (e) partner violence. 
reaching significance. For partner violence, significant interactions were generally noted across the full distribution of violence in two out of five MAOA SNPs (rs5906893 and rs979605).

\section{Discussion}

Our study shows evidence of a moderating effect of the MAOA gene on antisocial outcomes in a population-based sample of young males. Higher risks for antisocial outcomes were observed in males carrying the MAOA low-frequency alleles (such as rs5906957; tag SNP) in comparison with high-frequency allele carriers for most outcomes when exposed to violence. This study extends previous investigations on two accounts.
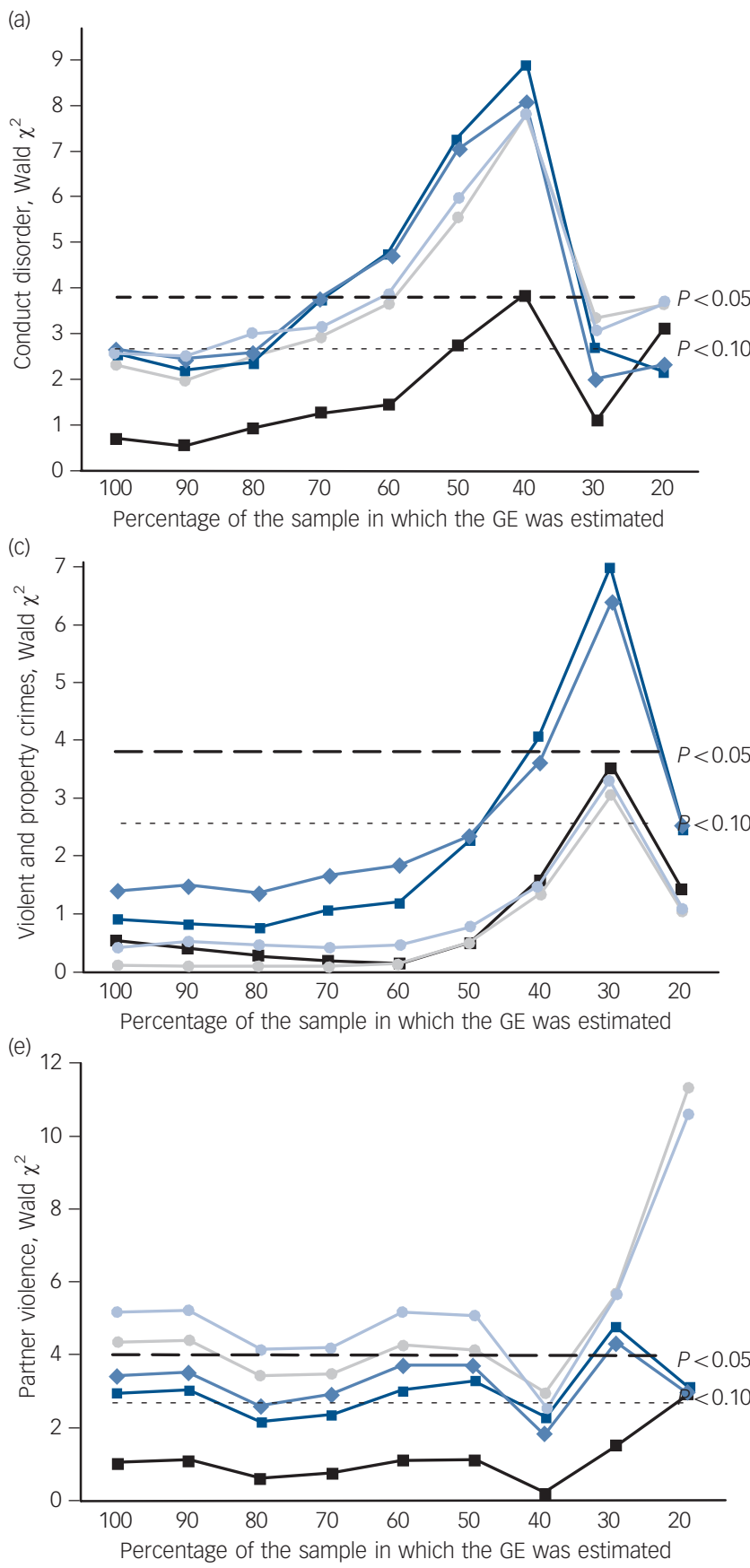

First, a number of observations indicate that the MAOA gene may affect the impact of violence on antisocial outcomes once a certain level of violence was experienced. Among them are the detection of non-linear interactions between MAOA SNPs and violence for conduct disorder, antisocial personality symptoms and partner violence. Significant quadratic associations between violence and antisocial outcomes in low-frequency allele carriers but not among high-frequency allele carriers also points to that possibility. These findings are in line with a diathesis-stress model in which genetic liabilities are more likely to be expressed under adverse circumstances. In the absence of a conceptual model specifying the levels of violence at which the genetic moderation is expected to take place, we conducted exploratory analyses
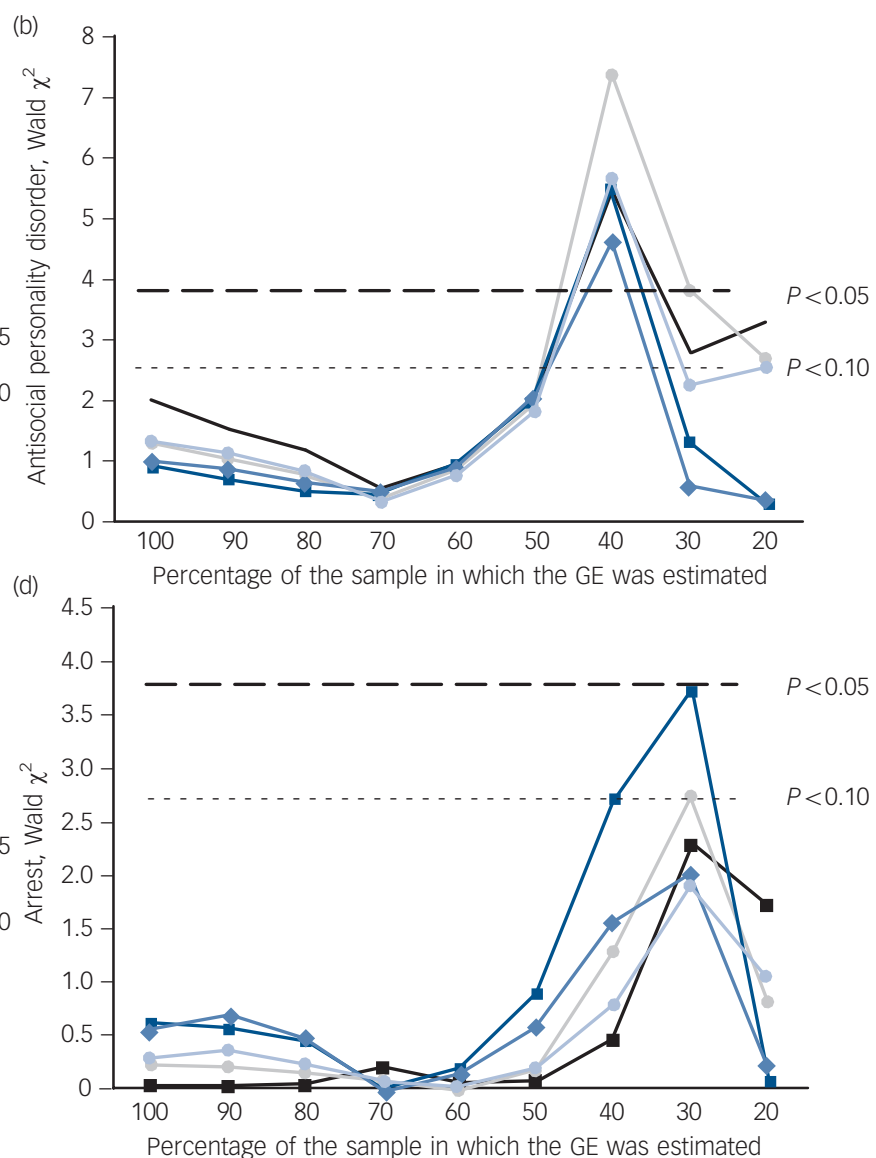

Fig. 2 Overview of the variation in the strength of the interactions between the monoamine oxidase A (MAOA) single nucleotide polymorphisms (SNPS) and exposure to violence on antisocial outcomes when estimated in the total sample (across the full distribution) and according to increasingly high level of exposure (per deciles).

(a) Conduct disorder, (b) antisocial personality disorder, (c) violent and property crimes (d) arrest, and (e) partner violence. GE, gene $\times$ environment interaction. 
testing whether the interactions between the MAOA gene and violence varied according to level of exposure. This strategy was suggested by Weder et al who found a shifting contribution of the MAOA gene on inattention, aggression and rule-breaking behaviours as a function of the levels of trauma experienced. ${ }^{15}$ Large variation in the magnitude of the interaction was noted for all outcomes, with the exception of partner violence for which the interaction remained generally stable (and significant for two SNPs out of five). Collectively, these exploratory analyses allowed the detection of significant interactions for antisocial personality symptoms and property-violent crimes that would otherwise have been missed if linear interaction was assumed to take place across the distribution of violence. The possibility that a genetic moderation emerges once a certain threshold of violence was reached may depend on whether regulatory systems are affected incrementally (in a linear fashion) or only at higher levels of exposure. Models such as the biological sensitivity to the context propose non-linear associations between the environments and physiological outcomes. ${ }^{1}$ More generally, the idea of a striking increase in behavioural problems once a certain number of risk factors is present is not new. ${ }^{33}$ For example, Greenberg and colleagues reported a strong increase in conduct problems when three or more risk factors (such as poor parenting practices) were present. ${ }^{34}$ Because these risk factors are likely to be partially genetically mediated, we speculate that these associations may conceal non-linear GE interactions, as suggested in our findings. Closer attention to the level of violence experienced by participants may help to clarify the role of gene-environment interplay in the aetiology of antisocial behaviour. ${ }^{35}$

Our findings are thus partially consistent with those originally reported by Caspi and colleagues ${ }^{8}$ and others, ${ }^{10-12,16}$ who noted the impact of the MAOA genotype on antisocial behaviour in the context of maltreatment, but not otherwise. Other studies have, however, failed to replicate this finding. ${ }^{13,14}$ One source of these inconsistencies may lie in the contrast tested between individuals exposed to distinct levels of 'high' exposure to violence. Without an a priori hypothesis regarding the precise level of violence required to trigger the genetically mediated 'diathesis', caution may be warranted in creating subgroups of exposure according to arbitrary cut-off points.

Importantly, few studies have investigated interactions between the MAOA gene, violence and antisocial outcomes using markers other than the promoter MAOA variable number of tandem repeats (VNTR), functionally related with enzyme expression and amine concentration. ${ }^{13}$ Our findings suggest that five other loci (rs5906893, rs5906957, rs2283725, rs2072744 and rs979605) may act in a similar way for antisocial outcomes although direct comparisons could not be performed as information about the VNTR was not available for our participants. Two lines of evidence suggest that the VNTR and these loci are linked. First, Ducci et al genotyped the VNTR as well as several other MAOA SNPs and found that rs979605 and the VNTR were in high linkage disequilibrium (D' 0.95). ${ }^{36}$ Of note, this study was conducted in Southwest American Indians, which is not an isolated population with a defined founder effect, such as the French Canadians. Among French Canadians, linkage disequilibrium values between these variants are likely to be higher. Second, in Haploview (4.2), the MAOA region (HapMap v2 Release 21) in the CEU sample, and two of our selected SNPs (rs5906893 and rs5906957) are both in a haplotype block that extends far upstream of the MAOA gene (beyond the VNTR). Future studies exploring the extent to which non-linear interactions may exist would benefit from examining haplotypes including both the identified SNPs and the VNTR.
Second, we observed distinct patterns of GE between antisocial outcomes. Whereas symptoms of conduct disorder and antisocial personality, property-violent crimes and to a certain extent the history of arrest (albeit not significant) followed a pattern of findings suggesting that the genetic diathesis is not present across the distribution of violence but is only restricted to higher levels of violence, distinct findings were noted for partner violence. For that phenotype, the effect of the MAOA genotype appeared to be incremental, with no inflexion point at higher levels of exposure. To the best of our knowledge, no studies have yet tested the moderating role of the MAOA gene on violence occurring in the context of intimate relationships. It is, however, possible that the genetic aetiology of intimate partner violence may be different from other antisocial outcomes. To begin with, the heritability of partner violence is less than half of those generally reported for antisocial behaviour $(16 \%$ v. $40-50 \%))^{37}$ Also, enduring vulnerabilities for partner violence, such as depression, antisocial behaviour and hostility ${ }^{38}$ (all of which being under partial genetic influence) were shown to influence partner violence through couple conflicts and negative relationship attributions, ${ }^{39}$ which may complicate even more the description of the pathways by which genes influence these behaviours. Additional studies investigating specifically partner violence are needed to shed further light on its genetic basis.

\section{Limitations}

A few features of the study might have constrained the findings. First, a number of measures of antisocial outcomes and exposure to violence have been collected concurrently through self-reports. The use of a mono-method strategy and recall biases thus could have inflated associations between them. However, these potential biases could not explain away the main effects of the MAOA gene and should not have otherwise tainted the findings obtained for the symptoms of conduct disorder and antisocial personality (assessed in semi-structured interviews). By and large, the similar patterns of findings emerge across antisocial outcomes suggesting that the impact of such bias should be minimal. Second, because our measure of violence encompassed all experiences that have occurred prior to 18 years of age, we could not contrast the effect of childhood $v$. adolescence exposure to violence. Finally, despite evidence suggesting that the selected SNPs relate to the MAOA promoter VNTR, their functional role on $M A O A$ activity remains to be demonstrated. In the same vein, the recurrence of similar patterns of findings across the selected SNPs should be interpreted cautiously given their level of linkage disequilibrium. Nevertheless, the emergence of distinct findings between the SNPs suggests that our analytical strategy allowed a sensitive test of the impact of genetically based differences within the MAOA gene on antisocial outcomes.

\section{Directions for future research}

This study extends previous research by showing that the genetic moderation of the MAOA gene may not be present across the full distribution of violence but emerges at a certain level and vary according to different antisocial outcomes. Future studies should investigate the cognitive, emotional and neurophysiological mechanisms detecting and translating the individual's vulnerability to violence, test whether they catalyse the expression of genetically based differences in antisocial behaviour and whether these mechanisms are themselves likely to vary across individuals.

\section{Funding}

I.O.-M. is a Canadian Institute of Health Research's New Investigator award holder. 
Isabelle Ouellet-Morin, PhD, School of Criminology, Université de Montréal \& Research Center of the Montreal Mental Health University Institute, Montréal and Research Group on Child Psychosocial Maladjustment, Université de Montréal Montréal, Canada; Sylvana M. Côté, PhD, Research Group on Child Psychosocia , Montréal, Department of Social and Preventive Medicine, Université de Montréal, Montréal, Canada and International Laboratory for Child and Adolescent Mental Health Development, INSERM U669, Paris, France; Frank Vitaro, PhD, Research Group on Child Psychosocial Maladjustment, Université de Montréal, Montréal and School of Psychoéducation, Université de Montréal, Montréal, Canada; Martine Hébert, PhD, Department of Sexology, Université du Québec à Montréal, Montréal, Québec, Canada; René Carbonneau, PhD, Research Group on Child Psychosocial Maladjustment, Université de Montréal, Montréal, Canada; Éric Lacourse, PhD, School of Criminology, Université de Montréal \& Research Center of the Montreal Mental Health University Institute Montréal, Research Group on Child Psychosocial Maladjustment, Université de Montréal, Montréal, Canada and Department of Sociology, Université de Montréal \& Research Center of the Sainte-Justine University Hospital, Montréal, Canada; Gustavo Turecki, MD, PhD, The McGill Group for Suicide Studies, Douglas Hospital Research Center, Montréal, Québec, Canada; Richard E. Tremblay, PhD, Research Group on Child Psychosocial Maladjustment, Université de Montréal, Montréal, Canada, International Laboratory for Child and Adolescent Mental Health Development, INSERM U669, Paris, France, Department of Pediatrics, Psychiatry and Psychology, Université de Montréal, Montréal, Canada and School of Public Health, Physiotherapy and Population Science, University College Dublin, Ireland

Correspondence: Isabelle Ouellet-Morin, PhD, School of Criminology, Université de Montréal Research Center of the Montreal Mental Health University Institute and the Research Group on Child Maladjustment, C.P. 6128, succursale Centre-ville, Montréal QC, H3C 3J7, Canada. Email: isabelle.ouellet-morin@umontreal.ca

First received 14 Dec 2014, final revision 29 Jan 2015, accepted 23 Feb 2015

\section{References}

1 Boyce TW, Ellis BJ. Biological sensitivity to context: I. An evolutionarydevelopmental theory of the origins and functions of stress reactivity. Dev Psychopathol 2005; 17: 271-301.

2 Belsky J, Bakermans-Kranenburg MJ, van Ijzendoorn MH. For better and for worse: differential susceptibility to environmental influences. Curr Dir Psychol Sci 2007; 16: 300-4.

3 Wilson HW, Stover CS, Berkowitz SJ. Research review: the relationship between childhood violence exposure and juvenile antisocial behavior: a meta-analytic review. J Child Psychol Psychiatry 2009; 50: 769-79.

4 Rhee SH, Waldman ID. Genetic and environmental influences on antisocial behavior: a meta-analysis of twin and adoption studies. Psychol Bull 2002; 128: $490-529$.

5 Hicks BM, South SC, Dirago AC, lacono WG, McGue M. Environmental adversity and increasing genetic risk for externalizing disorders. Arch Gen Psychiatry 2009; 66: 640-8.

6 Jaffee SR, Caspi A, Moffitt TE, Dodge KA, Rutter M, Taylor A, et al. Nature $\times$ nurture: genetic vulnerabilities interact with physical maltreatment to promote conduct problems. Dev Psychopathol 2005; 17: 67-84.

7 Moffitt TE, Caspi A, Rutter M. Measured gene-environment interactions in psychopathology: concepts, research strategies, and implications for research, intervention, and public understanding of genetics. Perspect Psychol Sci 2006; 1: 5-27.

8 Caspi A, McClay J, Moffitt TE, Mill J, Martin J, Craig IW, et al. Role of genotype in the cycle of violence in maltreated children. Science 2002; 297: 851-4.

9 Buckholtz JW, Callicott JH, Kolachana B, Hariri AR, Goldberg TE, Genderson M, et al. Genetic variation in MAOA modulates ventromedial prefrontal circuitry mediating individual differences in human personality. Mol Psychiatry 2008; 13: 313-24.

10 Foley DL, Eaves L, Wormley B, Silberg JL, Maes HH, Kuhn J, et al. Childhood adversity, monoamine oxidase a genotype, and risk for conduct disorder. Arch Gen Psychiatry 2004; 61: 738-44.

11 Kim-Cohen J, Caspi A, Taylor A, Williams B, Newcombe R, Craig IW, et al. MAOA, maltreatment, and gene-environment interaction predicting children's mental health: new evidence and a meta-analysis. Mol Psychiatry 2006; 11: 903-13.

12 Fergusson DM, Boden JM, Horwood L, Miller A, Kennedy MA. Moderating role of the MAOA genotype in antisocial behaviour. Br J Psychiatry 2012; 200: $116-23$.

13 Haberstick BC, Lessem JM, Hopfer CJ, Smolen A, Ehringer MA, Timberlake D, et al. Monoamine oxidase A (MAOA) and antisocial behaviors in the presence of childhood and adolescent maltreatment. Am J Med Genet B Neuropsychiatr Genet 2005; 135: 59-64.

14 Young SE, Smolen A, Hewitt JK, Haberstick BC, Stallings MC, Corley RP, et al. Interaction between MAO-A genotype and maltreatment in the risk for conduct disorder: failure to confirm in adolescent patients. Am J Psychiatry 2006; 163: 1019-25.

15 Weder N, Yang BZ, Douglas-Palumberi H, Massey J, Krystal JH, Gelernter J, et al. MAOA genotype, maltreatment, and aggressive behavior: the changing impact of genotype at varying levels of trauma. Biol Psychiatry 2009; 65 417-24.

16 Nilsson KW, Sjoberg RL, Damberg M, Leppert J, Ohrvik J, Alm PO, et al. Role of monoamine oxidase A genotype and psychosocial factors in male adolescent criminal activity. Biol Psychiatry 2006; 59: 121-7.

17 Enoch MA, Steer CD, Newman TK, Gibson N, Goldman D. Early life stress, MAOA, and gene-environment interactions predict behavioral disinhibition in children. Genes Brain Behav 2010; 9: 65-74.

18 Tremblay RE, Loeber R, Gagnon C, Charlebois P, Larivée S, LeBlanc M. Disruptive boys with stable and unstable high fighting behavior patterns during junior elementary school. J Abnorm Child Psychol 1991; 19: 285-300.

19 The International HapMap Consortium. The International HapMap Project. Nature 2003; 426: 789-96.

20 de Bakker PI, Yelensky R, Pe'er I, Gabriel SB, Daly MJ, Altshuler D. Efficiency and power in genetic association studies. Nat Genet 2005; 37 1217-23.

21 Carlson CS, Eberle MA, Rieder MJ, Yi Q, Kruglyak L, Nickerson DA. Selecting a maximally informative set of single-nucleotide polymorphisms for association analyses using linkage disequilibrium. Am J Hum Genet 2004; 74: 106-20.

22 Desjardins B. Ethnic homogeneity of the Quebec population during the French regime. Cah Québé Démogr 1990; 19: 63-76.

23 Strauss MA, Hamby SL, Finkelhor D, Moore DW, Runyan D. Identification of child maltreatment with the parent-child conflict tactics scales: development and psychometric data for a national sample of American parents (CTSPC) Child Abuse Negl 1998; 22: 249-70.

24 Felitti VJ, Anda RF, Nordenberg D, Williamson DF, Spitz AM, Edwards V, et al. Relationship of childhood abuse and household dysfunction to many of the leading causes of death in adults. The Adverse Childhood Experience (ACE) Study. Am J Prev Med 1998; 14: 245-58.

25 Hébert M. Adaptation Francaise du Adverse Childhood Experience (ACE) Study Questionnaire et du Sexually victimized Children Questionnaire de Finkelhor (1979) [French Adaptation of the Adverse Childhood Experience (ACE) Study Questionnaire and of the Finkelhor's Sexually Victimised Children Questionnaire]. Document inédit, 2000.

26 Lacelle C, Hebert M, Lavoie F, Vitaro F, Tremblay RE. Sexual health in women reporting a history of child sexual abuse. Child Abuse Negl 2012; 36: 247-59.

27 Pagani LS, Tremblay RE, Nagin D, Zoccolillo M, Vitaro F, McDuff P. Risk factor models for adolescent verbal and physical aggression toward mothers. Int J Behav Dev 2004; 28: 528-37.

28 Shaffer D, Fisher $\mathrm{P}$, Lucas CP, Dulcan MK, Schwab-Stone ME. NIMH Diagnostic Interview Schedule for Children Version IV (NIMH DISC-IV): description, differences from previous versions, and reliability of some common diagnoses. J Am Acad Child Adolesc Psychiatry 2000; 39: 28-38.

29 Valla JP, Breton JJ, Bergeron L, Gaudet N, Berthiaume C, Saint-Georges M, et al. Quebec Survey on Mental Health of Youths aged 6 to 14: Summary Report. Hôpital Rivière-des-Prairies, Santé Québec and the Ministère de la Santé et des Services Sociaux, Gouvernement du Québec, 1994

30 Robins LN, Helzer JE, Cottler L, Goldring E. The Diagnostic Interview Schedule, version III-R. Washington University, 1989.

31 Horney J. Criminal events and criminal careers: an integrative approach to the study of violence. In The Process and Structure of Crime: Criminal Events and Crime Analysis (eds R Meier, LW Kennedy, VF Sacco): 141-67. Transaction, 2000.

32 Livesley WJ, Jackson DN. The internal consistency and factorial structure of behaviors judged to be associated with DSM-III personality disorders. Am J Psychiatry 1986; 143: 1473-4.

33 Rutter M. Protective factors in children's responses to stress and disadvantage. In Primary Prevention of Psychopathology, Vol3: Social Competence in Children (eds MW Kent, JE Rolf): 49-74. University of New England Press, 1979.

34 Greenberg MT, Speltz ML, DeKlyen M, Jones K. Correlates of clinic referral for early conduct problems: variable- and person-oriented approaches. Dev Psychopathol 2001; 13: 255-76.

35 Rutter M. Genes and Behavior: Nature-Nurture Interplay Explained. Wiley-Blackwell 2006.

36 Ducci $F$, Enoch MA, Hodgkinson $C$, Xu K, Catena M, Robin RW, et al. Interaction between a functional MAOA locus and childhood sexual abuse predicts alcoholism and antisocial personality disorder in adult women. Mol Psychiatry 2008; 13: 334-47.

37 Hines DA, Saudino KJ. Genetic and environmental influences on intimate partner aggression: a preliminary study. Violence Vict 2004; 19: 701-18.

38 Ouellet-Morin I, Fisher HL, York-Smith M, Fincham-Campbell S, Moffitt TE, Arseneault $L$. Intimate partner violence and new-onset depression: a longitudinal study of women's childhood and adult histories of abuse. Depress Anxiety 2015; 32: 316-24.

39 Marshall $A D$, Jones $D E$, Feinberg ME. Enduring vulnerabilities, relationship attributions, and couple conflict: an integrative model of the occurrence and frequency of intimate partner violence. J Fam Psychol 2011; 25: 709-18. 